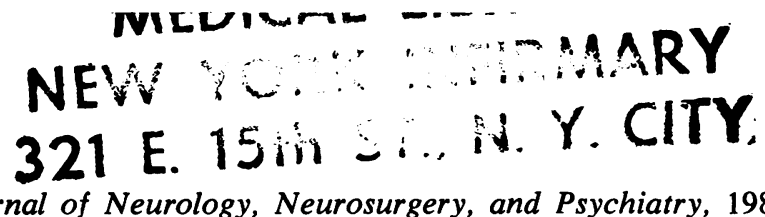

Journal of Neurology, Neurosurgery, and Psychiatry, 1980, 43, 97-101

\title{
Neck-tongue syndrome on sudden turning of the head
}

\author{
JAMES W LANCE AND MICHAEL ANTHONY \\ From the Division of Neurology, The Prince Henry Hospital, Little Bay, \\ and the School of Medicine, University of New South Wales, Sydney, Australia.
}

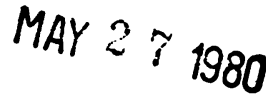

SUMMARY A syndrome of unilateral upper nuchal or occipital pain, with or without numbness in these areas, accompanied by simultaneous ipsilateral numbness of the tongue is explicable by compression of the second cervical root in the atlantoaxial space on sharp rotation of the neck. Afferent fibres from the lingual nerve travelling via the hypoglossal nerve to the second cervical root provide a plausible anatomical explanation for compression of that root causing numbness of half the tongue.

Four patients have been encountered in whom sudden rotation of the neck induced a sharp pain on one side of the upper neck or occiput, followed immediately by transient ipsilateral numbness of the tongue. The only reference to any comparable patient that we could find is made by Cyriax in his Textbook of Orthopaedic Medicine. ${ }^{1} \mathrm{He}$ mentions two patients, one of whom, a woman aged 45 years, experienced repeated bouts of pain in the occiput and left side of the neck brought on by turning her head sharply to the right. Simultaneously, the tongue and the back of her palate went numb, remaining so for about a minute. The other patient felt pins and needles in the tongue only. $\mathrm{He}$ attributes this phenomenon to "a third cervical root-pain with unusually extensive symptoms" but gives no hint of the anatomical pathway thought to be implicated.

The distinctive nature of the syndrome, the lack of previous attention to it, and the quest for a logical explanation provided the genesis of this report.

\section{Case Reports}

CASE 1 A man aged 26 years had been subject to symptoms on sudden rotation of the neck since a blow on the head when 8 years old. At that time he had been struck by a children's

Address for reprints: Professor JW Lance, Division of Neurology, The Prince Henry Hospital, Little Bay, Sydney, NSW 2036.

Accepted 9 July 1979 swing in the midfrontal region and had lacerated his forehead. Shortly afterwards he complained of numbness of the right half of the tongue as well as numbness and weakness of the right hand. The numbness persisted for about an hour but the hand remained clumsy for several days. As far as he could recall, this early episode was not associated with headache.

Ever since then he had been subject to a sharp pain in the upper neck on the right side on sudden rotation of the neck, most commonly to the left but sometimes to the right. Simultaneously he noticed numbness of the right side of the tongue (but not the face, cheeks or lips) and of the right little and ring fingers, which lasted for a few seconds only. The neck pain faded away over a period of 30 seconds. The attacks recurred every three months until the age of 13 years, since when the frequency reduced to once or twice each year. On three occasions during his school days he experienced severe neck pain for a few days after turning a somersault. He had never experienced crepitus of the neck. Physical examination was normal without any restriction of neck movement.

Radiographs of the neck at the age of 12 years (including tomograms of the upper cervical vertebrae) showed a glissade of the second on the third vertebra, considered to be normal for his age, and anteromedial bosses of bone on the condylar processes of the occiput representing a minor anomaly in occipital assimilation. There was no evidence of subluxa- 
tion or of ligamentary laxity in the upper cervical spine.

CASE 2 A boy age 15 years noticed pain in the occipital region on sudden neck rotation six or seven times in the past 12 months. A violent neck movement to right or left, while swimming, bowling, playing softball, or swinging on parallel bars caused a sharp pain in the right occipital region, shooting upwards "like a line up the back of the head," with a transient feeling of faintness. On the last occasion the right half of the tongue became numb and felt as though it were twisted sideways in the mouth. The sensation lasted as long as the occipital pain-for a few seconds only. After the pain had gone he was left with a "soft" feeling in the right occipital region. Several years previously he had experienced an ache in his neck after lying back on a car seat but there was nothing else of relevance in his history. Examination disclosed no abnormality. His neck was fully mobile. Radiography of the cervical spine including tomography of the atlanto-occipital and atlantoaxial joints was completely normal. An isotope brain scan was also normal.

CASE 3 A youth aged 17 years suffered intermittently from left occipital pain on violent rotation of the neck for three years, associated with numbness of the left half of the tongue for the past 18 months. On turning his neck sharply to one side or other (commonly to the right) while swimming or playing football or table tennis he noticed a tearing pain in the left side of the back of his neck which radiated over the left occipital region, followed immediately by a tingling burning feeling over this area. For the last 18 months the onset of the pain was followed immediately by the sensation of numbness appearing simultaneously in the left occiput and left half of the tongue, wearing off together over a period of fifteen seconds. These attacks recurred about once a week.

On other occasions, when he was sitting in a relaxed posture, his head "fell back" on the neck so that his face was looking partly upwards and to the right. This displacement of the head occurred suddenly with a click that he could feel but not hear. The neck felt uncomfrom side to side to free himself from this unpleasant sensation. These episodes took place about twice a day. Once in two or three months backward displacement of the head was fortable until he flexed it and turned his head associated with tingling in the fingers of the left hand lasting for less than a second.

The neck moved freely in all directions without crepitus, and full examination of the nervous and other systems was completely normal. Radiography of the cervical spine, including tomography of the upper vertebrae, was completely normal.

CASE 4 A girl aged 15 years began to experience pains in the left side of the upper neck on suddenly turning her head to the left when she was 12 years old. The pains lasted for about one minute at a time and had no accompaniments. Nine months after the onset similar movements of the head induced pain associated with numbness of the upper part of the neck and the mastoid area on the left side and numbness of the left side of the tongue. The pain continued to be short-lived but the numbness of the neck and tongue would last for three to five minutes. The attacks of pain and numbness were brought on by turning the head to the left and relieved by either keeping the head still or tilting it to the right side. An occasional attack still occurs whenever the patient turns her head to the left unwittingly. Complete neurological examination showed nothing abnormal and movements of the cervical spine were not restricted. Radiographs of the skull showed no abnormality but those of the cervical spine demonstrated fusion of the spinous processes of the atlas to the adjoining occipital bone.

\section{Discussion}

The four patients described were all young and experienced sharp pain in the upper neck, occiput, or both areas together on sharp rotation of the neck, accompanied by numbness of the tongue on the same side and other symptoms (table 1).

The site of pain suggests irritation of the second and third cervical roots, which, with the first root, are linked together by communicating fibres known as the posterior cervical plexus. In two patients pain followed by numbness or the sensation of "softness" on one side of the occiput clearly points to disturbance of the second cervical root, which is particularly vulnerable to compression in its course between atlas and axis during excessive rotation of the neck. ${ }^{2}$ Simultaneous numbness of the tongue on the same side is more difficult to explain 
Summary of patients and their episodic symptoms

\begin{tabular}{|c|c|c|c|c|}
\hline Case No. & 1 & 2 & 3 & 4 \\
\hline Sex & $\mathbf{M}$ & $\mathbf{M}$ & $\mathbf{M}$ & $\mathbf{F}$ \\
\hline Age of onset (years) & 8 & 14 & 14 & 12 \\
\hline Present age (years) & 26 & 15 & 17 & 15 \\
\hline \multicolumn{5}{|l|}{ Pain: } \\
\hline Neck & right & - & left & left \\
\hline Occiput & - & right & left & - \\
\hline \multicolumn{5}{|l|}{ Dysaesthesiae: } \\
\hline Neck & - & - & $\begin{array}{l}\text { left } \\
\text { (tingling) }\end{array}$ & $\begin{array}{l}\text { left } \\
\text { (numbness) }\end{array}$ \\
\hline Occiput & - & $\begin{array}{l}\text { right } \\
\text { ("soft feeling" }\end{array}$ & $\begin{array}{l}\text { left } \\
\text { (numbness) }\end{array}$ & 一 \\
\hline Tongue & $\begin{array}{l}\text { right half } \\
\text { (numbness) }\end{array}$ & $\begin{array}{l}\text { right half } \\
\text { (numbness) }\end{array}$ & $\begin{array}{l}\text { left half } \\
\text { (numbness) }\end{array}$ & $\begin{array}{l}\text { left half } \\
\text { (numbness) }\end{array}$ \\
\hline Fingers & $\begin{array}{l}\text { right little, } \\
\text { ring fingers } \\
\text { (numbness) }\end{array}$ & - & $\begin{array}{l}\text { left fingers } \\
\text { (tingling with head } \\
\text { "falling back") }\end{array}$ & - \\
\hline \multicolumn{5}{|l|}{ Usual duration: } \\
\hline $\begin{array}{l}\text { Pain } \\
\text { Dysaesthesiae }\end{array}$ & $\begin{array}{l}30 \mathrm{~s} \\
\text { seconds }\end{array}$ & $\begin{array}{l}\text { seconds } \\
\text { seconds }\end{array}$ & $\begin{array}{l}15 \mathrm{~s} \\
15 \mathrm{~s}\end{array}$ & $\begin{array}{l}60 \mathrm{~s} \\
3-5 \mathrm{~min}\end{array}$ \\
\hline Precipitating neck rotation & left > right & left or right & right $>$ left & left \\
\hline Neck pain at other times & + & + & & - \\
\hline Evidence for craniospinal anomaly & radiological (minor) & - & $\begin{array}{l}\text { clinical } \\
\text { (head "falling back") }\end{array}$ & radiological \\
\hline
\end{tabular}

since there is no conclusive evidence in man of afferent fibres from the lingual nerve entering the central nervous system by the second or third cervical roots.

Numbness or tingling around the mouth, cheiro-oral paraesthesiae, is common in vertebrobasilar insufficiency, ${ }^{3}$ and migraine. ${ }^{4}$ Numbness may affect the tip of the tongue but we have never known it affect one half of the tongue in isolation, nor have we seen it reported. In carotid insufficiency one half of the tongue may become numb as part of hemianaesthesia of the face ${ }^{6}$ but does not occur on its own. For these reasons and the fact that, in our patients, numbness of half of the tongue appeared at the same moment as numbness of the ipsilateral neck or occiput, it is not possible to invoke vascular occlusion by neck rotation as a mechanism, and cne must seek a direct neural connection.

The lingual nerve forms loops of communication with the hypoglossal nerve as the two course together over the hyoglossus muscle below the tongue. ${ }^{7}$ The hypoglossal nerve in turn is connected with a loop between the first and second cervical roots (fig 1). There is thus the possibility of afferent impulses travelling from the lingual nerve via the hypoglossal nerve to the second cervical root, and hence of numbness of one half the tongue being experienced on compression of that root. The proximity of the glossopharyngeal nerve and the presence of communications between the pharyngeal plexus and the hypoglossal nerve provide a similar means of explaining the numbness of the back of the palate described by one of Cyriax's patients.
There is some experimental evidence to support this hypothesis. Afferent discharges have been recorded from the hypoglossal nerve during stretching of the tongue in cats ${ }^{8}$ and monkeys, while Adatia and Gehring ${ }^{10}$ showed that position sense and control of tongue movement were retained in human subjects after bilateral blockade of inferior alveolar and lingual nerves. Thus afferent nerve fibres from the tongue, notably those concerned with proprioception, appear to be conveyed from the tongue via the hypoglossal nerve. Moreover, Bowman and Combs ${ }^{11}$ found that in monkeys hypoglossal afferent fibres enter the central nervous system by the second and third cervical roots. There is also anatomical evidence that afferent fibres travel in the rabbit hypoglossal nerve $\mathrm{e}^{12}$ and that some afferent fibres from the hypoglossal nerve pass through the first cervical root in the rabbit ${ }^{13}$ and the second cervical root in the monkey. ${ }^{14}$ The passage of some afferent nerve fibres from the tongue to the hypoglossal nerve and thence to one or more of the upper three cervical roots has therefore both anatomical and physiological confirmation from animal experimentation. Sherrington ${ }^{15}$ made a relevant observation on dissecting a human foetus with "an extreme degree of spinal bifida." Concerning the hypoglossal nerve, he stated: "tracing the normal-looking nerve-trunk backwards however it seems to be almost exclusively formed by a branch from the 2nd cervical ganglion and another from the vagus below one vagus ganglion."

The afferent fibres from the tongue which traverse the hypoglossal nerve to enter the cen- 


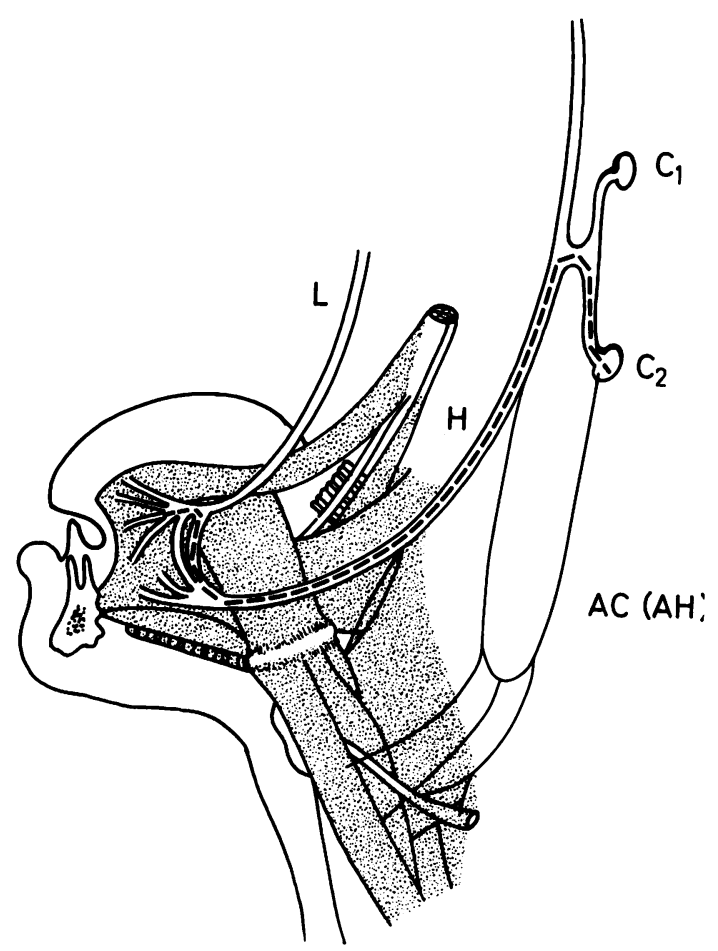

Figure Proposed anatomical connection to explain ipsilateral numbness of tongue accompanying compression of second cervical root. Interrupted lines indicating possible path taken by afferent fibres from lingual nerve via hypoglossal nerve to second cervical root have been superimposed on a diagram modelled after Fig 885, p 1007, of the eighth edition of Cunningham's Text-Book of Anatomy (by permission of Oxford University Press). $L=$ Lingual nerve. $H=H y p o g l o s s a l$ nerve. $A C(A H)=A n s a$ cervicalis (ansa hypoglossi), $C_{1}, C_{2}=$ First and second cervical roots.

tral nervous system through the second cervical root appear to have a proprioceptive function, so that it is surprising to find that sudden compression of these fibres in man gives rise to a sensation described as "numbness" by the patients, although our second patient remarked that the tongue felt as though it were twisted sideways in the mouth.

The mechanical disability of the upper cervical spine that induces compression of the second cervical root on sudden rotation of the neck almost certainly involves some degree of unilateral subluxation of the facets of the atlanto-axial joint. Two of our patients had minor anomalies of the upper cervical spine. A third patient (case 3) described a curious episodic "falling back" of the head so that the head turned upwards and to the right, indicating instability of the upper cervical spine. The cause of numbness in the ipsilateral hand during such transient subluxation in two patients is probably attributable to tension on the meninges irritating the lower cervical roots on the same side. Paraesthesiae in the fingers was a symptom of atlantoaxial subluxation in six of 22 patients with rheumatoid arthritis of the upper cervical spine described by Robinson. ${ }^{16}$ None of Robinson's patients complained of numbness of the occiput or tongue, presumably because the displacement of atlas on axis in rheumatoid arthritis is symmetrical, caused by weakness of the transverse ligament which normally tethers the odontoid process in place. Such bilateral subluxation would throw tension on the cervical roots bilaterally in contrast to the sudden compression of one root between atlas and axis provided by an excessive rotational movement in a relatively normal spine. Another report of atlantoaxial dislocation in rheumatoid arthritis and ankylosing spondylitis emphasises the frequency of pain in the upper cervical, suboccipital, and occipital regions. ${ }^{17}$ Many patients with ankylosing spondylitis described the sensation of "falling forwards" (not backwards) of the head. Sharp and Purser ${ }^{17}$ commented that some rotation and tilting of the head was usually present through asymmetrical slipping of atlantoaxial facets. This posture is similar to that described by the third of our patients when his head felt as though it were slipping backwards on the cervical spine.

$\mathrm{McRae}^{18}$ described the symptoms of 68 patients with bony abnormalities at the craniospinal junction. Occipital or suboccipital pain was experienced by $26 \%$ and paraesthesiae of the fingers by $13 \%$ of these patients. More serious symptoms, such as transient weakness of one or both legs $(32 \%)$ and ataxia of gait $(9 \%)$ had led to a diagnosis of multiple sclerosis in $31 \%$ of the cases. Carella ${ }^{19}$ reported occipital headache and a variety of neurological symptoms in 26 of 51 patients with minor anomalies of the atlas. In neither report is there mention of numbness of one half of the tongue.

In conclusion, a syndrome has been described in four young people which is attributable to instability of the upper cervical spine causing unilateral compression of the second (and possibly third) cervical root. An anatomical connection between the lingual nerve and second cervical root via the hypoglossal nerve provides a plausible explanation for numbness of one half the tongue being a symptom of such compres- 
sion. The syndrome has been benign thus far in one patient followed for 18 years from the onset of symptoms, presumably because symptoms are caused by asymmetrical slipping of the facets, compressing a root but not the spinal cord. Nevertheless, caution is advisable in counselling patients about sporting and other physical activity in view of episodes of quadriplegia described by $\mathrm{McRae}^{18}$ in more severe anomalies of the upper cervical spine.

We thank Associate Professor C R R Watson of the School of Anatomy, University of New South Wales, for his guidance in obtaining the relevant anatomical literature. The figure was drawn by Mrs F Rubiu and photographed by the Department of Medical Illustration, University of New South Wales.

\section{References}

1 Cyriax J. Textbook of Orthopacdic Medicine. 4th ed. Volume 1, p 158. London: Cassell, 1962.

2 Hunter CR, Mayfield FH. Role of the upper cervical roots in the production of pain in the head. Am J Surg 1949; 78:743-51.

3 Marshall J. A survey of occlusive disease of the vertebrobasilar arterial system. In: Vinken PJ, Bruyn GW, eds. Handbook of Clinical Neurology. Volume 12, 1972; 1-12.

4 Klee A. A clinical study of migraine with particular reference to the most severe cases. Copenhagen: Munksgaard, 1968.

5 Sachs OW. Migraine: Evolution of a Common Disorder. London: Faber and Faber, 1970.

6 Fisher CM. Clinical syndromes in cerebral arterial ozclusion. In: Fields WS, ed. Pathogenesis and treatment of cerebrovascular disease. Springfield: Thomas, 1961; 1-31.

7 Durward A. Peripheral nervous system. In:
Brash JC, Jamieson EB, eds. Cunningham's Text-Book of Anatomy. London: Oxford University Press, 1943; 991, 1006-7.

8 Cooper S. Afferent impulses in the hypoglossal nerve on stretching the cat's tongue. J Physiol (Lond) 1954; 126:32P.

9 Bowman JP, Combs CM. Discharge patterns of lingual spindle afferent fibres in the hypoglossal nerve of the rhesus monkey. Exper Neurol 1968; 21:105-19.

10 Adatia AK, Gehring EN. Proprioceptive innervation of the tongue. J A nat 1971; 110:215-20.

11 Bowman JP, Combs CM. The cerebrocortical projection of hypoglossal afferents. Exper Neurol 1969; 23:291-301.

12 Boyd JD. The sensory component of the hypoglossal nerve in the rabbit. J Anat 1941; 75: $330-45$.

13 Yee J, Harrison F, Corbin KB. The sensory innervation of the spinal accessory and tongue musculature in the rabbit. J Comp Neurol 1939; 70:305-14.

14 Corbin KB, Harrison F. The sensory innervation of the spinal accessory and tongue musculature in the rhesus monkey. Brain 1939; 62:191-7.

15 Sherrington CS. On the anatomical constitution of nerves of skeletal muscles; with remarks on recurrent fibres in the ventral spinal nerve-root. J Physiol (Lond) 1894; 17:211-58.

16 Robinson HS. Rheumatoid arthritis-atlantoaxial subluxation and its clinical presentation. Can Med Assoc J 1966; 94:470-7.

17 Sharp J, Purser DW. Spontaneous atlanto-axial dislocation in ankylosing spondylitis and rheumatoid arthritis. Ann Rheum Dis 1961; 20:47-77.

18 McRae DL. Bony abnormalities at the craniospinal junction. In: Ojemann RG, ed. Clin Neurosurg. Baltimore: Williams \& Wilkins, 1969; 16:356-75.

19 Carella A. Slight anomalies of the atlas, their pathogenetic meaning. Neuroradiol 1972; 3: 224-7. 